\title{
MEDICAL AND SURGICAL MANAGEMENT OF ANAL FISSURE - A PROSPECTIVE STUDY
}

\author{
Chitra Subramanian'1, Ashoka Chakravarthi Damodharan'2, Prabhu Kumarappan Chibandaram³, Manoharan Appavu4, \\ Gourab Kundu
}

${ }^{1}$ Associate Professor, Department of Surgery, Madurai Medical College.

${ }^{2}$ Assistant Professor, Department of Surgery, Madurai Medical College.

${ }^{3}$ Postgraduate, Department of Surgery, Madurai Medical College.

${ }^{4}$ Postgraduate, Department of Surgery, Madurai Medical College.

5 Postgraduate, Department of Surgery, Madurai Medical College.

\section{ABSTRACT}

\section{BACKGROUND}

The aim of this study is to assess the effectiveness of different modes of treatment of acute and chronic anal fissure and determine the efficacy of different medical treatments and surgeries in the treatment of anal fissure.

\section{MATERIALS AND METHODS}

Between 2011 and 2015 for a period of five years, 2003 patients with typical anal fissure were selected and completed the study. Majority of acute anal fissure patients (97\%) and $28 \%$ of chronic fissure patients were initially treated conservatively with nifedipine, diltiazem ointment for 8 to 12 weeks. Persisting symptoms or recurrence were indicated for surgery. Remaining patients underwent lateral internal sphincterotomy. During the followup (12 months) healing rates, symptoms, incontinence and adverse effects were prospectively recorded.

\section{RESULTS}

Most acute fissure patients were successfully managed conservatively $97 \%$ with only 14 patients (3\%) undergone LIS as primary treatment. On the contrary, majority of chronic fissure patients need surgical management (72\%) as primary treatment. For conservative management, $0.2 \%$ diltiazem and $2 \%$ nifedipine were used with equal healing rates without any side effects with persisting symptoms seen in $24 \%$ among acute fissure and $53 \%$ patients among the chronic fissure patients showing higher success rate for acute fissure than chronic patients. Recurrence rate for nifedipine and diltiazem was 14 and $12 \%$ respectively. Among the patients undergone LIS, healing rate of more than $97 \%$ achieved for both open and closed technique LIS and recurrence rate of less than $0.5 \%$ achieved for both techniques.

\section{CONCLUSION}

Acute anal fissure can be managed effectively with medical treatment. Nifedipine found to be more effective as first line treatment for acute fissure. Lateral internal sphincterotomy is far more effective than medical treatment in the management of chronic fissure with significant increase in healing rate and very less recurrence compared to medical management while avoiding any risk of incontinence with no significant difference between open or closed technique.

\section{KEYWORDS}

Anal Fissure, Nifedipine and Diltiazem Ointment, Lateral Internal Sphincterotomy.

HOW TO CITE THIS ARTICLE: Subramanian C, Damodharan AC, Chibandaram PK, et al. Medical and surgical management of anal fissure - a prospective study. J. Evolution Med. Dent. Sci. 2016;5(95):6990-6995, DOI: 10. 14260/jemds/2016/1581

\section{BACKGROUND}

Anal fissures are commonly encountered in routine colorectal practice and are the most common cause of severe anal pain. Developments in the pharmacological understanding of the internal anal sphincter have resulted in more conservative approaches towards treatment of acute anal fissure.

Financial or Other, Competing Interest: None.

Submission 07-10-2016, Peer Review 05-11-2016,

Acceptance 11-11-2016, Published 28-11-2016.

Corresponding Author:

Dr. Chitra Subramanian,

Shri Prasanna Illam,

Model House No. 3,

North $3^{\text {rd }}$ Cross Street,

Anna Nagar,

Madurai-625020,

Tamilnadu.

E-mail: chitra.madurai@gmail.com

DOI: $10.14260 /$ jemds $/ 2016 / 1581$
Nifedipine found to be more effective as first line treatment for acute fissure. Lateral internal sphincterotomy was found to be most effective in chronic anal fissures. This study was conducted to determine the efficacy of different medical treatment and surgery in the treatment of acute and chronic anal fissure respectively.

\section{MATERIALS AND METHODS}

This prospective study included 2003 patients with acute and chronic anal fissures presented to the Surgical Outpatient Department of Madurai Medical College from 2011 to 2015.

Patients were managed both pharmacologically as OPD patients and surgically as admitted patients.

All patients included in the study underwent a thorough per anal examination with a well lubricated finger with use of local anaesthetic jelly. Sigmoidoscopy reserved patients with altered bowel habits to rule out inflammatory bowel disease.

All patients instructed to apply small amounts of $0.2 \%$ diltiazem or $2 \%$ nifedipine in soft white paraffin to the anoderm with finger tips or applicator after passing stools. 
All patients were encouraged to take high fibre diet, plenty of fluids, warm sitz baths twice a day and regular toilet training. Patients evaluated at two-week intervals and at each visit the symptoms' control, adverse effects and fissure status were recorded. If there was symptomatic relief or the fissure healing was in progress, the medical treatment continued for a total duration of eight weeks. Afterwards, the patients were given the option to resume the treatment in case of recurrence or abandon this therapy and consider surgical intervention. Two followup visits, at two-month interval were arranged after the completion of the initial therapy to establish the longterm effectiveness of treatment. Lateral internal Sphincterotomy is the surgical procedure done for all patients. Majority of patients underwent surgery under spinal anaesthesia (74\%) and local anaesthesia (26\%). Surgery done with patient in lithotomy position. Sphincterotomy done at 3 o'clock position for all patients. No anal packing done for any patients. Patients allowed full oral feed six hours after surgery. Operated patients were nursed in wards thereafter. Postoperative analgesia Injection Tramadol $100 \mathrm{mg}$ single dose given on day of surgery. Patients discharged after 24 hours. Tablet Paracetamol, antibiotics ciprofloxacin $500 \mathrm{mg}$ BD, metronidazole $400 \mathrm{mg}$ TDS and chymoral forte given for 3 days. They were advised sitz bath three times daily and stool softener liquid paraffin $30 \mathrm{~mL}$ HS for 4 weeks. They were advised to report to 2 weeks following surgery and followed up for 6 months. Patients were declared cured in case of complete symptomatic relief with fissure healing.

\section{Inclusion Criteria}

All patients with typical symptoms and signs of anal fissure were selected.

\section{Exclusion Criteria}

Patients with history of previous surgery in the anal canal, inflammatory bowel disease, associated haemorrhoids and perianal abscess were excluded.

\section{RESULTS}

In our study total of 2003 patients with anal fissure were included, of which 470 patients were acute fissure patients and 1533 chronic fissure patients.

There were total 1367 male (68\%) and 636 female (32\%) with the ratio of $2.14: 1$ with predominant incidence was observed in 20 - 40 years of age [1102 patients - 55\%], 746 male (54.5\% of male subjects) and 356 female (56\% of female subjects). Douglas et al shows among women the peak incidence occurred during adolescence and young adulthood, but among men the incidence was highest during middle age which is similar to our result. 1

\begin{tabular}{|c|c|c|c|}
\hline Age & Male & Female & Total \\
\hline$<10$ yrs. & 5 & 9 & 14 \\
\hline $10-20$ & 46 & 45 & 91 \\
\hline $20-30$ & 318 & 162 & 480 \\
\hline $30-40$ & 428 & 194 & 622 \\
\hline $40-50$ & 308 & 123 & 431 \\
\hline $50-60$ & 171 & 74 & 245 \\
\hline$>70$ & 91 & 29 & 120 \\
\hline Total & 1367 & 636 & $\mathbf{2 0 0 3}$ \\
\hline \multicolumn{4}{|c|}{ Table 1. Age and Sex Distribution } \\
\hline
\end{tabular}

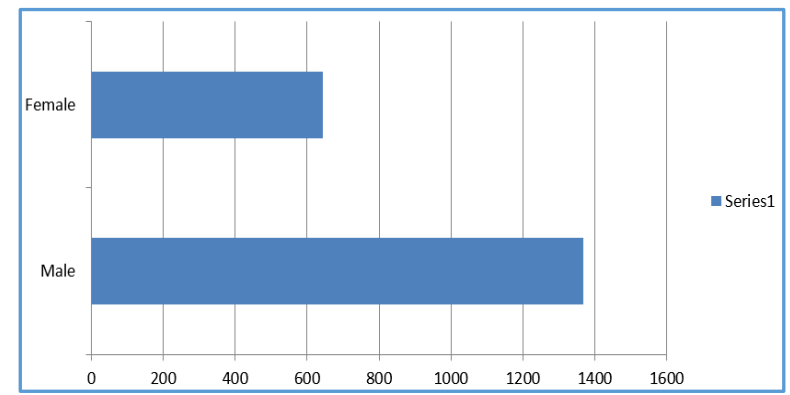

Figure 1

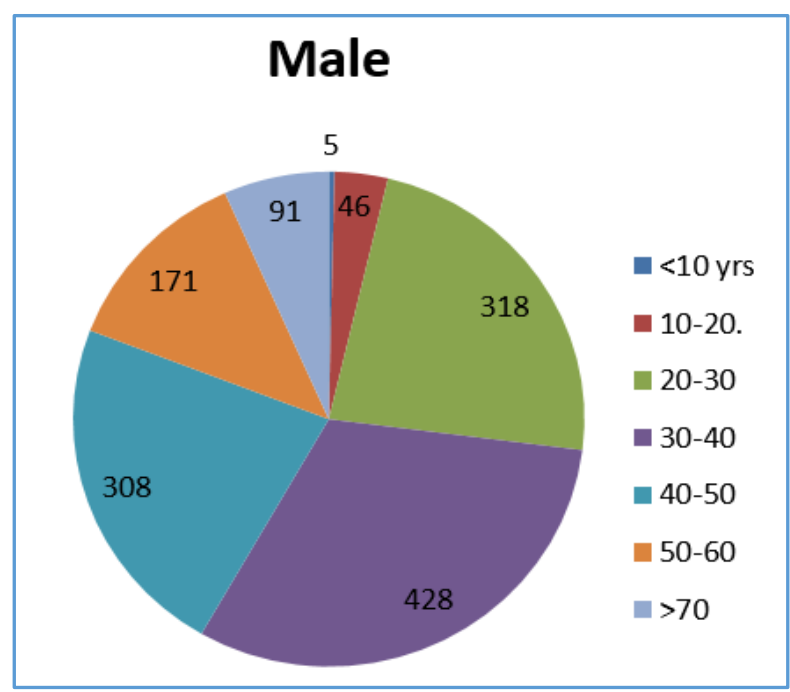

Figure 2

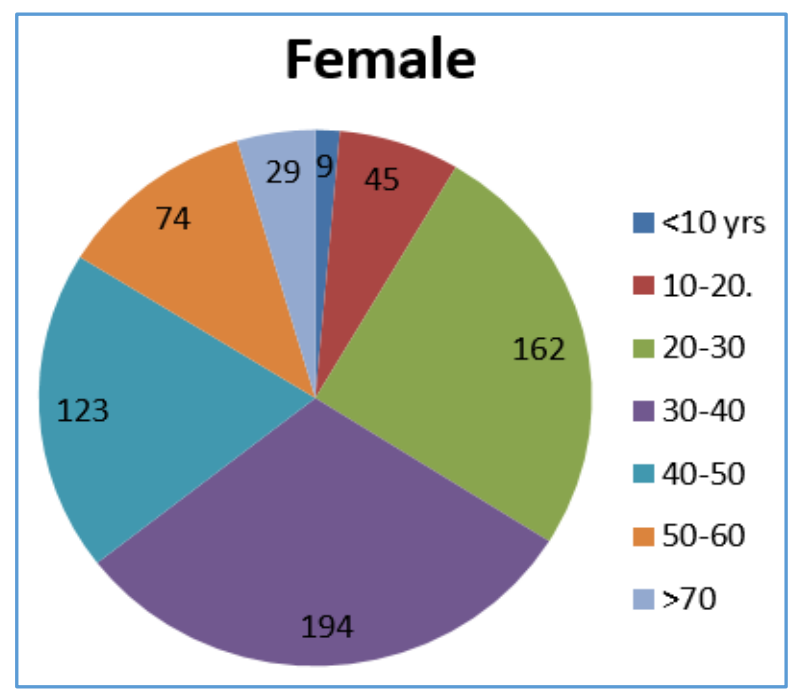

Figure 3

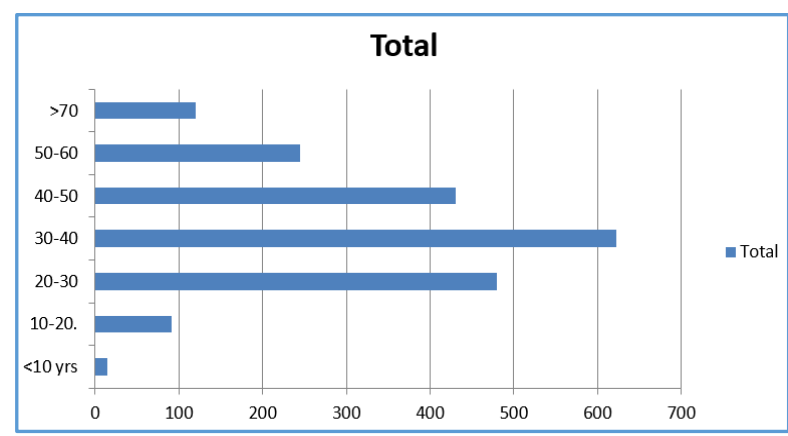

Figure 4 
Majority of the patients in our study had posterior fissure [1541 patients (77\%)] and 263 patients had anterior fissure (13\%), 174 patients had combined anterior and posterior fissure (9\%) and 25 patients had multiple fissure (1\%). Karen and Fleshner et al shows approximately $90 \%$ of anal fissures in both men and women are located posteriorly in the midline. Anterior fissures occur in $10 \%$ of patients, more commonly women. Less than $1 \%$ of fissures is located off a midline position or multiple in numbers, which is similar to our results. $^{2}$

Mode of presentation in our study was pain (100\%), bleeding (81\%), constipation (61\%), straining during passing stools in $(27 \%)$ patients, itching (6\%), discharge (infected fissure) $1.2 \%$.

Hananel and Gordon et al shows dominant presenting symptoms as pain $(90.8 \%)$ and bleeding $(71.4 \%)$, straining during defecation (29.3\%). Other presenting symptoms included pruritus (6.2\%), swelling $(3.3 \%)$ and discharge (1.1\%), which matches our study results. ${ }^{3}$

\section{Conservative Management \\ Acute Fissure}

In our study out of 470 patients who had acute anal fissure, 456 patients $(97 \%)$ were treated conservatively with warm sitz bath, stool softener, high fibre diet and topical diltiazem or nifedipine ointment application; 14 patients (3\%) were subjected to lateral internal sphincterotomy as $1^{\text {st }}$ line of treatment.

Healing of acute fissure with conservative treatment was achieved in 347 patients (76\%) of 456 patients. Among the conservative group, 196 patients (43\%) of 456 were given topical diltiazem cream and remaining 260 patients (57\%) were given topical nifedipine cream. Fissure healing was achieved in 145 patients (74\%) in topical diltiazem group and in $202(77 \%)$ in topical nifedipine group.

94 patients came with persisting symptoms after 8 weeks of medical management and were advised surgery; 75 out of 94 patients underwent LIS, remaining 19 patients were not willing for surgery and continued medical management, 15 patients lost to follow up.

At 6 months followup, 14 patients from diltiazem group (10\% of healed patients) and 18 patients of nifedipine group ( $9 \%$ of healed patients) came with recurrent fissure and underwent LIS.

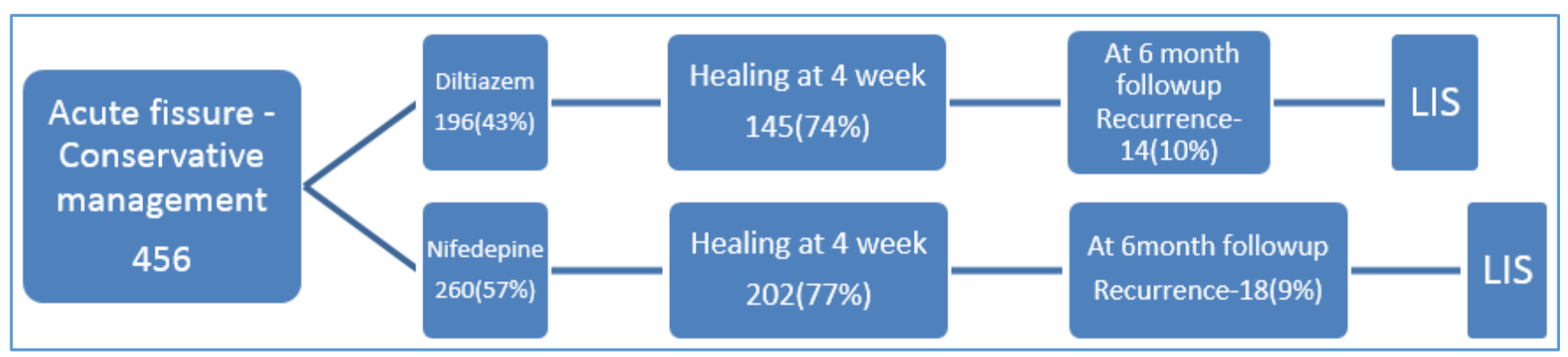

\section{Chronic Fissure}

In our study, out of 1533 patients who had chronic anal fissure, 429 patients (28\%) had fissure of more than 8 weeks without any other complications and no pathological changes such as hypertrophic papillae, sentinel pile or indurated base were treated conservatively with diet modification, warm sitz bath and topical diltiazem or nifedipine ointment application.

Healing of fissure was achieved in 202 patients (47\%) of 429 patients by medical management; 164 patients (38\%) of 429 were given topical diltiazem cream and 265 patients (62\%) were given topical nifedipine cream. Fissure healing was achieved in 85 patients (52\%) in topical diltiazem group and in 142 (53\%) in topical nifedipine group. Knight J S et al shows similar results.
Carapetti et al and Kocher et al shows $67 \%$ and $77 \%$ of patients respectively got healed after using topical diltiazem. Golfam et al, healing was achieved in $70 \%$ of patients after 4 weeks of treatment with nifedipine.

Of the remaining 227 patients who underwent medical treatment, 212 patients on followup failed to respond to medical management, had persisting symptoms and offered LIS, 32 patients were not willing for surgery and continued medical treatment. Remaining 180 patients underwent LIS; 15 patients lost to followup.

At 6 months followup, 11 patients from diltiazem group (14\% of healed patients) and 17 patients from nifedipine group (12\% of healed patients) came with recurrence and were offered LIS as treatment.

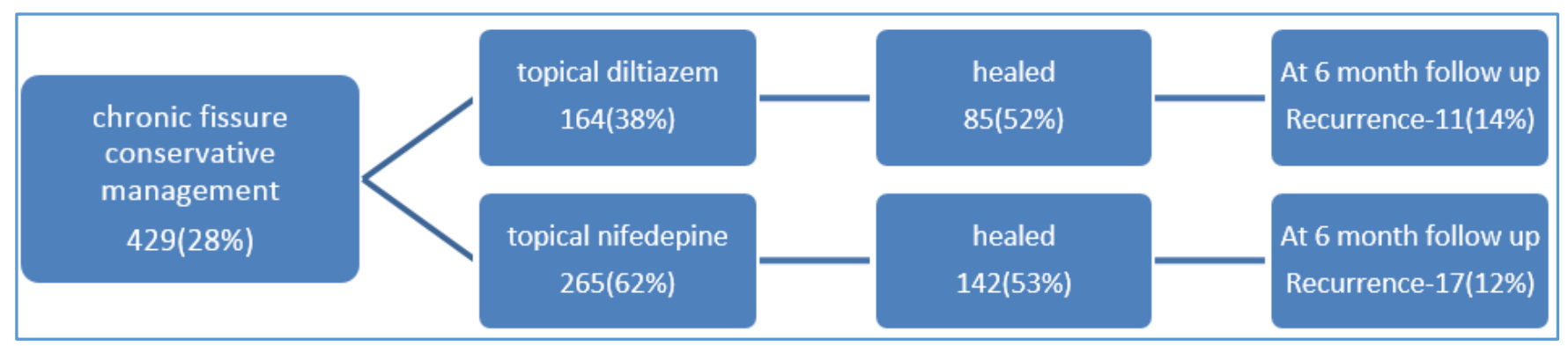




\section{Surgical Management}

\section{For Acute Fissure}

In our study among all the cases of acute fissure (470 patients), in $97 \%$ cases (456 patients) conservative medical management was done and on the basis of severe pain and as patients insisted on surgery $3 \%$ patients' (14 patients) surgery was done as $1^{\text {st }}$ line of treatment.

$20 \%$ patients (94 patients) from conservatively treated group failed to respond to medical management and were offered Lateral Internal Sphincterotomy (LIS); 75 out of 94 patients underwent LIS. Remaining 19 patients were not willing for surgery and continued medical management; 15 patients were lost to followup.

At 6 months followup, 14 patients from diltiazem group ( $10 \%$ of healed patients) and 18 patients of nifedipine group ( $9 \%$ of healed patients) came with recurrent fissure and underwent LIS.

Totally, 121 patients with acute fissure underwent LIS (14 primary surgery +75 failed medical management +32 recurrent fissure following medical treatment).

Out of 121 patients, 77 patients (63\%) underwent open LIS and (37\%) 44 patients underwent closed LIS. Relief of symptoms seen in $100 \%$ of patients underwent LIS. Healing rate was compared in both open and closed LIS group over $4^{\text {th }}$ week of followup and was found that healing rate was $97 \%$ (32 out of 33 patients) in closed and 3\% (1 patient) had delayed healing. Among open LIS group, healing rate was $97.5 \%$ (54 out of 56 patients) and 2 patients had delayed healing. None of the patients in both closed and open group had incontinence recurrence.

Surgical treatment patients - 121 (14 primary surgery +75 failed medical management +32 recurrent fissure following medical treatment).

\begin{tabular}{|c|c|c|c|}
\hline $\begin{array}{c}\text { Sl. } \\
\text { No. }\end{array}$ & Outcome & $\begin{array}{c}\text { Closed LIS } \\
\text { (44 Patients) }\end{array}$ & $\begin{array}{c}\text { Open LIS } \\
\text { (77 patients) }\end{array}$ \\
\hline & Pain relief & & \\
1. & Healing rate & $100 \%$ & $100 \%$ \\
2. & Delayed healing & $97 \%$ & $97.5 \%$ \\
3. & Haematoma & $3 \%$ & $2.5 \%$ \\
4. & Flatus incontinence & $3 \%$ & $0 \%$ \\
5. & Bleeding & $0 \%$ & $0 \%$ \\
6. & Wound site & $0 \%$ & $0 \%$ \\
7. & infection & $0 \%$ & $3 \%$ \\
8. & Failure/Recurrence & $0 \%$ & $0 \%$ \\
9. & Faecal soiling & $0 \%$ & $0 \%$ \\
10. & Faecal & $0 \%$ & $0 \%$ \\
\hline \multicolumn{3}{|c|}{ Table 2. Acute Fissure Surgical Management } \\
\hline
\end{tabular}

\section{For Chronic Fissure}

1104 patients $(72 \%)$ with chronic anal fissure of symptoms more than 8 weeks and associated with sentinel skin tag, hypertrophic papillae and indurated base were advised surgery and offered lateral internal sphincterotomy as $1^{\text {st }}$ line of treatment.

Among the conservatively treated patients, 180 patients failed to respond to medical management and came with persistent symptoms and offered LIS, 32 patients were not willing for surgery and continued medical treatment; 15 patients lost to followup.
At 6 months followup after medical treatment, 11 patients from diltiazem group ( $14 \%$ of healed patients) and 17 patients from nifedipine group (12\% of healed patients) came with recurrence and were offered LIS as treatment.

Totally 1212 patients with chronic fissure underwent LIS (1104 primary surgery +180 failed medical management +28 recurrent cases).

Among surgically treated patients, 34\% (412 patients) underwent closed LIS and 66\% (800 patients) underwent open LIS. On $4^{\text {th }}$ week healing rate was $96 \%$ (395 patients) for closed and $97.5 \%$ (780 patients) for open method. Richard et al shows healing rates of sphincterotomy range from $92 \%$ to $100 \%$ with majority of fissures healing within 2 months, which is similar to our result.4-13 There was no incidence of incontinence for both flatus and faeces in both surgery groups. Haematoma was seen in 5 patients $(1.2 \%)$ who underwent closed technique of LIS. Bleeding occurred in 12 patients $(1.5 \%)$ in open LIS group. Wound site infection seen in 3 patients $(0.4 \%)$ in open group. Recurrence seen in 2 patients from open group and 1 patient from closed group; 3 recurrent patients managed conservatively. Brown et al shows recurrence rates range from $0 \%$ to $3.3 \%$ in patients who underwent LIS. ${ }^{12-14}$

Surgical treatment patients - 1212 (1104 primary surgery +180 failed medical management +28 recurrent cases) .

\begin{tabular}{|c|c|c|c|}
\hline $\begin{array}{c}\text { Sl. } \\
\text { No. }\end{array}$ & Outcome & $\begin{array}{c}\text { Closed LIS } \\
\mathbf{( 4 1 2} \\
\text { Patients) }\end{array}$ & $\begin{array}{c}\text { Open LIS } \\
\mathbf{( 8 0 0} \\
\text { Patients) }\end{array}$ \\
\hline 1. & Pain relief & $100 \%$ & $100 \%$ \\
2. & Healing rate & $96 \%$ & $97.5 \%$ \\
3. & Delayed healing & $3.8 \%$ & $2.25 \%$ \\
4. & Haematoma & $1.2 \%$ & $0 \%$ \\
5. & Flatus incontinence & $0 \%$ & $0 \%$ \\
6. & Bleeding & $0 \%$ & $1.5 \%$ \\
7. & Wound site infection & $0 \%$ & $0.4 \%$ \\
8. & Failure/recurrence & $0.2 \%$ & $0.25 \%$ \\
9. & Faecal soiling & $0 \%$ & $0 \%$ \\
10. & Faecal incontinence & $0 \%$ & $0 \%$ \\
\hline \multicolumn{3}{|c|}{ Table 3. Chronic Fissure Surgical Management } \\
\hline
\end{tabular}

\section{DISCUSSION}

Anal fissure is a painful linear wound in the squamous epithelium of the anal canal distal to the dentate line. The incidence of anal fissures is around 1 in 350 adults. They occur equally in men and women and most often occur in young adults aged 15 to 40 . It is usually located in the posterior midline, but occurs anteriorly in a fifth or more of patients. It typically causes pain during defecation, which may last for 1 2 hours afterwards. ${ }^{14}$ The finding on physical examination is spasm of the anal canal due to hypertonia of the internal anal sphincter. It has been postulated that this may either be due to or be the result of ischaemia. ${ }^{13}$ Most anal fissures are caused by stretching of the anal mucosa beyond its capability. In adults fissures may be caused by constipation, the passing of large, hard stools or by prolonged diarrhoea as well as anal sex. Other causes of anal fissures include childbirth trauma in women or Crohn's disease. ${ }^{15}$

Fissures are defined as acute if present for less than 6 weeks, and they are defined as chronic if present for more than 6 weeks. ${ }^{16}$ Anal fissures may present with rectal pain described as burning, cutting or tearing that occurs during defecation. Bright red blood appears on the surface of stools and is present only in a small amount. 
Occasionally, blood is found on toilet paper after wiping. The patient may report no bleeding. ${ }^{17}$ The management aims to reduce anal tone. The initial approach is non-operative. Acute fissures rarely require surgical intervention and usually improve with conservative management.

Symptoms from an acute fissure often resolve within 10 14 days of conservative medical management; however, as long as 6 - 8 weeks may be necessary for the actual tear to heal.18 After 6 - 8 weeks, the fissure is considered chronic and more active measures such as chemical or surgical sphincterotomy may be considered. Among conservative treatment, diltiazem and nifedipine can be considered as firstline treatment. Surgical therapy is often reserved when conservative treatment fails to heal anal fissures. Surgery includes lateral sphincterotomy, advancement flap procedures and fissurectomy.19,20 By 1959, the 'standard internal sphincterotomy' comprised division of only half of the IAS (Internal Anal Sphincter) to the dentate line in its lateral or posterolateral part. Lateral sphincterotomy diminishes internal anal sphincter tone and thereby reduces anal canal pressure. This improves anal mucosal blood flow and promotes the healing of anal fissures. Apart from the associated risks and discomfort, surgery can cause incontinence. ${ }^{21}$

Anal advancement flap is indicated for patients with primary or recurrent fissures and for women with a complicated obstetric history with low resting anal canal pressure. This operation avoids further disruption to the internal sphincter and avoids factors that might otherwise jeopardise continence.22 Manual dilatation of the anus is a simple procedure and previously a popular treatment.

Incontinence is a concern and current opinion is that manual dilatation of the anus for the treatment of anal fissures is not recommended. ${ }^{23}$ Fissures associated with pregnancy are commonly located anteriorly and are often associated with low anal canal pressures. These secondary fissures are most appropriately treated by addressing the underlying disease process. ${ }^{24}$

\section{CONCLUSION}

Acute anal fissure can be managed effectively with medical treatment. Nifedipine is found to be more effective as first line treatment for acute fissure. Lateral internal sphincterotomy is far more effective than medical treatment in the management of chronic fissure with significant increase in healing rate and very less recurrence compared to medical management, while avoiding any risk of incontinence with no significant difference between open or closed technique.

\section{REFERENCES}

1. Mapel DW, Schum M, Worley AV. The epidemiology and treatment of anal fissures in a population-based cohort. BMC Gastroenterol 2014;14:129.

2. Zaghiyan KN, Fleshner P. Anal Fissure. Clin Colon Rectal Surg 2011;24(1):22-30.

3. Hananel N, Gordon PH. Re-examination of clinical manifestations and response to therapy of fissure-in-ano. Dis Colon Rectum 1997;40(2):229-33.

4. Poh A, Tan KY, Seow-Choen F. Innovations in chronic anal fissure treatment: a systematic review. World J Gastrointest Surg 2010;2(7):231-41.
5. Menteş BB, Irkörücü $\mathrm{O}$, Akin $\mathrm{M}$, et al. Comparison of botulinum toxin injection and lateral internal sphincterotomy for the treatment of chronic anal fissure. Dis Colon Rectum 2003;46(2):232-7.

6. Garcea G, Sutton C, Mansoori S, et al. Results following conservative lateral sphincteromy for the treatment of chronic anal fissures. Colorectal Dis 2003;5(4):311-4.

7. Tocchi A, Mazzoni G, Miccini M, et al. Total lateral sphincterotomy for anal fissure. Int J Colorectal Dis 2004;19(3):245-9.

8. Liratzopoulos N, Efremidou EI, Papageorgiou MS, et al. Lateral subcutaneous internal sphincterotomy in the treatment of chronic anal fissure: our experience. J Gastrointestin Liver Dis 2006;15(2):143-7.

9. Wiley M, Day P, Rieger N, et al. Open vs. closed lateral internal sphincterotomy for idiopathic fissure-in-ano: a prospective, randomized, controlled trial. Dis Colon Rectum 2004;47(6):847-52.

10. Jensen SL, Lund F, Nielsen OV, et al. Lateral subcutaneous sphincterotomy versus anal dilatation in the treatment of fissure in ano in outpatients: a prospective randomised study. Br Med J (Clin Res Ed)1984;289(6444):528-30.

11. Richard CS, Gregoire R, Plewes EA, et al. Internal sphincterotomy is superior to topical nitroglycerin in the treatment of chronic anal fissure: results of a randomized, controlled trial by the Canadian Colorectal Surgical Trials Group. Dis Colon Rectum 2000;43(8):1048-57.

12. Evans J, Luck A, Hewett P. Glyceryl trinitrate vs. lateral sphincterotomy for chronic anal fissure: prospective, randomized trial. Dis Colon Rectum 2001;44(1):93-7.

13. Brown CJ, Dubreuil D, Santoro L, et al. Lateral internal sphincterotomy is superior to topical nitroglycerin for healing chronic anal fissure and does not compromise long-term fecal continence: six-year follow-up of a multicenter, randomized, controlled trial. Dis Colon Rectum 2007;50(4):442-8.

14. Lindsey I, Jones OM, Cunningham $\mathrm{C}$, et al. Chronic anal fissure. Br J Surg 2004;91(3):270-9.

15. Sileri P, Mele A, Stolfi VM, et al. Medical and surgical treatment of chronic anal fissure: a prospective study. J Gastrointest Surg 2007;11(11):1541-1548.

16. Murshed KM, Siddique MI, Rahman MA. Effectiveness and complications of $0.2 \%$ Glyceryl trinitrate in the treatment of chronic anal fissure. Journ Bang Coll Phy Surg 2007;25(1):14-17.

17. Haq Z, Rahman M, Chowdhury RA, et al. Chemical sphicterotomy- first line of treatment for chronic anal fissure. Mymesingh Med J 2005;14(1):88-90.

18. Scholefied JH, Bock JU, Marla B, et al. A dose finding study with $0.1 \%, 0.2 \%$, and $0.4 \%$ glyceryltrinitrate ointment in patients with chronic anal fissures. Gut 2003;52(2):2649.

19. Bhardwaj R, Drye E, Vaizey C. Novel delivery of botulinum toxin for the treatment of anal fissures. Colorect Dis 2006;8(4):360-4.

20. Kocher HM, Steward M, Leather AJ, et al. Randomized clinical trial assessing the side effects of glyceryltrinitrate and diltiazem hydrochloride in the treatment of chronic anal fissure. Br J Surg 2002;89(4):413-7.

21. Mishra R, Thomas S, Maan MS, et al. Topical nitroglyerin versus lateral internal sphincterotomy for chronic anal 
fissure: prospective, randomized trial. ANZ J Surg 2005;75(12):1032-5.

22. Zubaeri BF, Baloch Q, Abro H. Glyceryl trinitrate ointment in the treatment of anal fissures. J Coll Physicians Surg Pak 1999;9:410-2.
23. Golligher J. Surgery of the anus, rectum and colon. $3^{\text {rd }}$ edn. London: Balliere Tindall 1984:170-91.

24. MacDonald A, Smith A, McNeill AD, et al. Manual dilatation of the anus. Br J Surg 1992;79(12):1381-2. 